\title{
BIBLIOGRAPHICAL ITEMS
}

The SEMIGROUP FORUM maintains a reprint file and would like to receive reprints of any article about semigroups which has appeared in another journal. Preprints are also welcome and will be listed under BIBLIOGRAPHICAL ITEMS. Below are listed such papers that have appeared in 1977-1979 that we have received recently:

Tamura, T., Notes on translational hulls of completely 0-simple semigroups, Tokyo Gakugei University, (1977) 73-83.

Strecker, R., Uber Duo-Halbgruppen, Wissenschaftliche Zeitschrift, 2 (1978) $275 \overline{-278 .}$

Quinkert, R., Uber Schreiersche Gruppenerweiterungen und ihre Kommutatorgruppen, Acta Sci. Math., 40 (1978) 327-345.

Haftendorn, Dorte, Additive kommutative und indempotente Halbringe mit Faktorbedingung, I, Publicationes Mathematicae 25 (1978) $\overline{107-116 .}$

Putcha, M.S., On linear algebraic Semigroups III ${ }^{+}$, submitted Ann.Math. Proceedings of The 2nd Sumposium on Semigroups, Tokyo Gakugei Univ. Nakjima, S., Translational hull of a generalized Brandt semigroups.

Yamada, M., Completely regular semigroups having certain properties.

Yoshida, R., McAlister representation of proper simple inverse semigroups.

Kobayashi, $Y$., On a problem of commutative nil semigroups.

Kuroki, N. , Fuzzy ideals and fuzzy bi-ideals in semigroups.

Iseki, K., On Griss type algebras.

Imaoka, T., The embedding of generalized inverse semigroups amalgams.

Saito, T., Fundamentally linearly ordered semigroups.

Numakura, $\mathrm{K} .$, Closedness of q-ideals in a compact and totally disconnected semigroups.

Fujiwara, T., Algebraically closed algebraic extensions in universal classes.

Tamura, T., Recent results and problems in commutative archimedean semigroups.

Lajos, S., (1, 2)-Ideal characterizations of certain classes of semigroups, Kobe University, 7(1979), 139-142.

Baird, B.B., Inverse semigroups of homeomorphisms are hopfian, Can. J. Math., 4, (1979) 800-807.

Szabo, L., A family of semigroups with increasing elements, Karl Marx University of Economics-Budapest, (1978), 1-18.

Lajos, S., Nagy, A., Szabo, L., Tilidetzke, R., Notes on semigroups $\underline{\text {, }}$ Karl Marx University of Economics- Budapest, (1978), I-28.

Lajos, S., On generalized bi-ideals in semigroups, Karl Marx Univ. of Economics-Budapest, $(1976), 335-340$.

Lajos, S., Characterizations of completely regular elements in semigroups, Acta scientiarum mathematicarum, (1978), 297-300.

Lajos, $\mathrm{S}_{\text {, On }}(\mathrm{m}, \mathrm{n})$-twin semigroups, Karl Marx University for Economics-Budapest, (1978), 1-3. 